\title{
DESVENDANDO AS FACES DA BIBLIOTECA ESCOLAR: UM ESTUDO SOBRE A PRODUÇÃO CIENTÍFICA
}

\author{
Edcleyton Bruno Fernandes da Silva \\ Mestrando em Ciência da Informação pelo PPGCI/UFPB \\ biblioebfs@yahoo.com.br \\ Gabriella Domingos de Oliveira \\ Mestranda em Ciência da Informação pelo PPGCI/UFPB \\ gabryellaholiveirah@gmail.com
}

\section{Resumo}

\begin{abstract}
Este artigo lança olhares sobre a produção científica na área de biblioteconomia através dos periódicos científicos. Busca mapear os periódicos científicos da área para identificar na literatura artigos que apresentam pesquisas sobre o incentivo à leitura. Apresenta dados quantitativos sobre a produção científica, bem comoqualitativos, por verificar a produção científica sobre o incentivo à leitura. Percebeu-se que a pesquisa científica sobre o incentivo à leitura tem se tornado escassa nos periódicos, de acordo com a amostra da pesquisa, entretanto ressalta-se que os periódicos específicos da área têm qualidade significativa, de acordo com os critérios de avaliação Qualis.
\end{abstract}

Palavras-chave: Biblioteca Escolar. Produção Científica. Periódico Científico.

\section{INTRODUÇÃO}

As bibliotecas constituem-se em um espaço de explosão do conhecimento pela capacidade de reunir em um só lugar informação que é capaz de construir sonhos e transformar realidades. Assim, sua composição é de extrema importância para uma sociedade, uma vez que se torna importante mola propulsora de formação cidadã, formação profissional e, ao mesmo tempo, aglomera aspectos culturais de uma comunidade.

A leitura é um elemento essencial na formação humana e vai além do quadro formativo, seja ele profissional ou acadêmico, notadamente contribui para formar cidadania e alimenta a cultura de uma nação/povo.No Brasil, a leitura não tem se destacado entre os indivíduos e isso não é um fato recente. Almeida Júnior (1997) aponta que esse problema está enraizado desde o período colonial e que medidas têm sido tomadas desde então para suprir tais necessidades, como, por exemplo, o trabalho de evangelização dos jesuítas, que tem em essência a prática de leitura.

Segundo dados do Programa Internacional de Avaliação de Alunos (PISA) ${ }^{1}$, em 2012 o Brasil apresentou baixa escala de crescimento de leitura em ambientes escolares relativos ao ano 2000, de forma mais específica, o percentual de média de leitura por aluno obteve um crescimento de menos de $3 \%$. Os resultados apontaram um maior equilíbrio na distribuição da faixa etária, ou seja, o número de alunos em séries com idade correta obteve

\footnotetext{
${ }^{1}$ Programa Internacional de Avaliação de Estudantes - éuma iniciativa de avaliação comparada, aplicada a estudantes na faixa dos 15 anos, idade em que se pressupõe o término da escolaridade básica obrigatória na maioria dos países. Disponível em: <http://portal.inep.gov.br/pisa-programainternacional-de-avaliacao-de-alunos> Acesso em: 15 set. 2016.
} 


\section{Anais do Encontro Paraibano de Biblioteca Escolar}

um crescimento graças às Políticas de Educação implantadas nos últimos anos.

Nesse cenário, visualizamos que aspectos da correção da faixa etária dos alunos no Brasil obtiveram êxito, entretanto, os índices de leitura não acompanharam esse desenvolvimento,mostrando que a educação alcançou resultados positivos, mas para isso não foram adotadas medidas de incentivo à leitura, o que pode acarretar no crescimento do analfabetismo funcional ${ }^{2}$ no Brasil. Frente a essa realidade, é preciso considerar que medidas devem ser tomadas, necessariamente, nas políticas de inclusão da leitura como princípio fundamental da formação escolar.

As bibliotecas, especificamente as escolares, têm um papel importante para mudar o quadro de leitura e de formação dos indivíduos. $\mathrm{O}$ incentivo à leitura deve ser tomado como uma ferramenta permanente tanto do educador quanto do bibliotecário. Segundo Araújo, Silva e Silva (2010), o Bibliotecário tem um papel importante e está habilitado para tal função, uma vez que este, em sua atribuição de mediador entre o usuário e a informação, auxilia no processo de busca e acesso à informação.

Outro aspecto importante que merece destaque é a produção científica, que aponta as pesquisas científicas mais recentes sobre a temática, para que, a partir de então, esta se torne uma variável importante do ponto de vista da contribuição para o conhecimento de uma determinada disciplina. Nesse contexto, destacamos o incentivo à leitura como uma das competências bibliotecárias, e que deve ser explorada nessa comunidade, sob a ótica da produção científica nessa temática.

Portanto, questiona-se:O que está sendo estudado/pesquisado sobre o incentivo à leitura? Quais periódicos se destacam na produção científica na temática incentivo à leitura? Esta pesquisa lança um olhar sobre dois aspectos fundamentais: quais são os

\footnotetext{
2 [...] o termo passou a ser utilizado para designar a capacidade de utilizar a leitura e a escrita para fins pragmáticos, em contextos cotidianos, domésticos ou de trabalho, muitas vezes colocado em contraposição a uma concepção mais tradicional e acadêmica, fortemente referida a práticas de leitura com fins estéticos e à erudição (RIBEIRO, 1997, p. 145).
}

periódicos científicos da área de Biblioteconomia no Brasil e, complementarmente, como se apresenta a produção científica sobre $\mathrm{o}$ incentivo à leitura.Para isso, será construído um quadro com os principais periódicos eletrônicos, bem como o que estão publicando sobre incentivo à leitura.

\section{BIBLIOTECAS ESCOLARES}

A biblioteca escolar é de suma importância para o desenvolvimento intelectual de crianças e adolescentes, pois é no ambiente escolar que iniciam-se as cognições de leitura e de conhecimento. Quando existem bibliotecas em escolas (sejam elas municipais, estaduais ou privadas) que sejam gerenciadas por bibliotecários especializados, este local fornecerá suporte pedagógico para os seus usuários. Assim, “a biblioteca é pretensamente local que reúne materiais necessários para a busca por informações, atividade que embasa (ou deveria embasar) o processo de pesquisa" (OLIVEIRA; CAMPELLO, 2016, p.181).

Os avanços em relação às bibliotecas escolares estão gradualmente sendo postos em prática, tanto em relação à sua importância efetiva na sociedade, quanto em pesquisas acadêmicas. Os pesquisadores começaram a enxergar essa realidade e a "fragilidade" em relação às pesquisas. Estas investigações, principalmente teóricas e práticas, em que conseguem-se enxergar os avanços, as dificuldades, os obstáculos e quem são os pares diante do universo de pesquisas acadêmicas. A biblioteconomia teve a inquietação de buscar esses "pares", e sua importância na biblioteca escolar estava também ligada com a teoria.

Oliveira e Campello (2016) construíram um diagnóstico temporal da angústia dos pesquisadores de biblioteconomia sobre a leitura e a biblioteca escolar: 


\begin{tabular}{|c|c|c|}
\hline Década de 1960 & & Década de 1970 \\
\hline $\begin{array}{l}\text { Os textos revelam o discurso de } \\
\text { bibliotecários que chamam para } \\
\text { si a responsabilidade pelo } \\
\text { desenvolvimento de uma gama } \\
\text { de habilidades cognitivas nos } \\
\text { estudantes e que se mostram } \\
\text { claramente conscientes de seu } \\
\text { papel no processo inovador de } \\
\text { aprendizagem }\end{array}$ & $\begin{array}{l}\text { Situam-se poucos trabalhos que, } \\
\text { além do discurso sobre a } \\
\text { importância da pesquisa escolar, } \\
\text { propõem atividades sistemáticas } \\
\text { para ensinar os alunos a usar a } \\
\text { biblioteca e as fontes de } \\
\text { informação. }\end{array}$ & $\begin{array}{l}\text { Uma terceira perspectiva surgiu } \\
\text { com a criação de cursos de Pós- } \\
\text { Graduação em Biblioteconomia } \\
\text { na década de } 1970 \text {, o que ensejou } \\
\text { a pesquisa na área e a } \\
\text { consequente araduão } \\
\text { bibliográfica. }\end{array}$ \\
\hline
\end{tabular}

Fonte:Adaptado de Oliveira e Campello, 2016, p. 182.

Nessa perspectiva, as pesquisas estão a cada momento sendo mais frequentes em relação às bibliotecas escolares. Uma realidade positiva, pois nestas discussões que podemser encontradas resoluções para problemas e aplicá-las na realidade.

Os fatos em relação às bibliotecas, na realidade, não são favoráveis. Pois estas não se encontram "preparadas", haja vista que as mesmas não têm apoios suficientes em reação à sua administração e crescimento, principalmente quando falamos em bibliotecas escolares públicas.

Sob tais contextos, no Brasil, prevaleceu o vazio legislativo em torno da biblioteca escolar e, mesmo tendo ocorrido ações pontuais e específicas, pouco foi feito por seu desenvolvimento. A inação histórica trouxe marcas para o tempo presente, em que a biblioteca escolar não é, efetivamente, tida como relevante; basta observar a carência quantitativa e qualitativa existente na cena educacional. (VIANA; PIERUCCINI, 2015, p. 131).

Compreende-se que existem defasagem e muitos obstáculos para que a biblioteca escolar consiga fazer o seu papel na educação da sociedade brasileira. Observamos aqui que existem muitas pesquisas, problemáticas e possíveis perspectivas de melhoramento. Porém o que é necessário fazer é juntar esforços políticos e sociais para que a mesma tenha seu papel de destaque e de disseminadora de conhecimento para crianças e jovens. Haja vista que estes, por sua vez, poderãoestar inclusos na sociedade informacional, gerando conhecimento desde pequenos.

\subsection{OS PERIÓDICOS CIENTÍFICOS COMO FONTES DE INFORMAÇÃO}

A utilização de fontes de informação confiáveis é necessária em todos os âmbitos da sociedade, principalmente em pesquisas científicas. Quando se encontra informações em fontes fidedignas, a pesquisa se torna mais "visível" e legítima. Isso propõe que a mesma é confiável, e que as informações que ela contém podem ser utilizadas como parâmetros de outras pesquisas ou possíveis soluções.

Diante da perspectiva do aumento da produção científica em relação ao tema proposto, já investigado e citado anteriormente, que cresceu conforme os programas de pós-graduação, onde o aumento das pesquisas sobre o tema veio com fortes propostas. Mueller; Campello; Dias (1996, p. 337) afirmam que a produção científica de uma área é "o requisito mais importante para o desenvolvimento da ciência". Quanto mais desenvolve ciência e pesquisas intelectuais, potencialmente irá desenvolver novas indagações e respostas para os impasses que as bibliotecas possuem. A "produção científica, que parece ser consolidada a partir de estudos e análises dos suportes documentais que veiculam as pesquisas em cada área" (DUARTE, 2003, p. 25).

A utilização de periódicos científicos possui relevância pelo fato de quesãoum canal científico e confiável que se atualiza constantemente na área de estudo, por ser publicado periodicamente (mensalmente, bimestral, trimestral, semestral e anual). Estes, por sua vez, consistem em um 


\section{Anais do Encontro Paraibano de Biblioteca Escolar}

importante canal de informação e científicas da área de Ciência da Informação, conhecimento científico para leitores.

\section{METODOLOGIA}

A metodologia consiste no "conjunto de atividades sistemáticas e racionais que, com maior segurança e economia, permite alcançar o objetivo, traçando o caminho a ser seguido" (LAKATOS, MARCONI, 2003, p. 83). Para isso ela é "desenvolvida mediante o concurso dos conhecimentos disponíveis e a utilização critérios de métodos, técnicas e outros procedimentos científicos" (GIL, 2002, p. 17).

Esta pesquisa é caracterizada como exploratória-descritiva, assim posto por Lakatos e Marconi (2003) como um estudo que descreve um ambiente e, ao mesmo tempo, expõe um determinado fenômeno de forma quantitativa e/ou qualitativade maneira sistemática.Desse modo, esta pesquisa lança olhares sobre a produção científica na área de biblioteconomia através dos periódicos científicos.

Por se tratar de uma pesquisa documental do tipo bibliográfica, uma vez que utilizará para a análise de materiais já publicados (GIL, 2002) a partir do mapeamento dos periódicos científicos da área buscou-se identificar na literatura artigos que apresentem pesquisas sobre o incentivo à leitura. Assim, esta investigação apresenta dados quantitativos sobre a produção científica, bem como para atender à característica qualitativados trabalhos serão analisados.

Para identificar os principais periódicos científicos da área de Biblioteconomia, visitou-se o portal $\mathrm{LTi}^{3}$, que apresenta o panorama das revistas científicas da área de Ciência da Informação nacionais e internacionais. Percebeu-se que há 62 revistas

\footnotetext{
${ }^{3} \mathrm{O}$ Laboratório de Tecnologias Intelectuais (LTi) é um projeto de pesquisa-ensino-extensão, com vistas ao desenvolvimento de ações que facilitem o acesso livre à informação científica e tecnológica, de modo a promover reflexões e propiciar competências em tecnologias intelectuais de produção, comunicação e uso dessa informação. <http://www.lti.pro.br/>.
}

\footnotetext{
${ }^{4}$ A pesquisa foi realizada entre os dias $15-20$ de agosto de 2016.
}

Entretanto, para o objeto desta pesquisa, consideram-se apenas as revistas de Biblioteconomia, totalizando noverevistas consideradas específicas em Biblioteconomia. A partir da leitura do item Foco e escopo, identificou-se que estas se apresentaram de forma expressiva em Biblioteconomia.Com base nestesnoveperiódicos, verificou-se a última edição de cada revista para identificar pesquisas que tratem de forma específica sobre o incentivo à leitura, para obter um panorama sobre a temática a partir da literatura científica.

\section{RESULTADOS DA PESQUISA}

A pesquisa resultou em nove periódicos científicos da área de Biblioteconomia, conforme o Quadro 2: 
Quadro 2: Periódicos científicos específicos em Biblioteconomia

\begin{tabular}{|l|c|c|}
\hline \multicolumn{1}{|c|}{ PERIÓDICO CIENTÍFICO } & $\begin{array}{c}\text { ARTIGOS NA } \\
\text { ÚLTIMA EDIÇÃO }\end{array}$ & QUALIS \\
\hline $\begin{array}{l}\text { BIBLOS - Revista do Instituto de Ciências Humanas e da } \\
\text { Informação }\end{array}$ & 6 & $\mathrm{~B} 3$ \\
\hline Biblionline & 10 & $\mathrm{~B} 1$ \\
\hline Biblioteca Escolar em Revista & 5 & - \\
\hline $\begin{array}{l}\text { Em Questão: Revista da Faculdade de Biblioteconomia e } \\
\text { Comunicação da UFRGS }\end{array}$ & 12 & $\mathrm{~B} 1$ \\
\hline $\begin{array}{l}\text { Encontros Bibli: Revista Eletrônica de Biblioteconomia e } \\
\text { Ciência da Informação }\end{array}$ & 9 & $\mathrm{~B} 1$ \\
\hline $\begin{array}{l}\text { Pesquisa Brasileira em Ciência da Informação e } \\
\text { Biblioteconomia }\end{array}$ & 5 & $\mathrm{~B} 1$ \\
\hline Revista ACB & 8 & $\mathrm{~B} 1$ \\
\hline Revista Brasileira de Biblioteconomia e Documentação & 5 & $\mathrm{~B} 1$ \\
\hline Revista Digital de Biblioteconomia e Ciência da Informação & 9 & $\mathrm{~B} 1$ \\
\hline TOTAL & 69 & - \\
\hline
\end{tabular}

Fonte: Dados da pesquisa, 2016.

De um total de 12 periódicos científicos (ativos e inativos), percebeu-se que uma publicação trata de forma específica sobre Bibliotecas Escolares, enove podem ser consideradas específicas de Biblioteconomia. Sete encontram-se indexadas com Qualis B1, o que representa um bom aspecto de qualidade nos artigos publicados na área de Biblioteconomia. Apenas uma possui Qualis
B3e uma não tem Qualis, conforme apresentado no quadro acima.

A pesquisa resultou em 69artigos publicados, somando-se todos os artigos das últimas edições das nove revistas, conforme o Quadro 2. Desses, apenas cinco exploram a temática biblioteca escolar, conforme $\mathrm{o}$ Quadro 3:

Quadro 3: Artigos com a temática Biblioteca Escolar/Leitura

\begin{tabular}{|l|l|l|}
\hline \multicolumn{1}{|c|}{ TÍTULO } & \multicolumn{1}{|c|}{ AUTORES } & PERIÓDICO \\
\hline Acervo enxuto para biblioteca escolar & $\begin{array}{l}\text { Moisés da Silva Cabete; } \\
\text { Nadja Polyana FelizolaCabete; } \\
\text { Daniel Reis Armond de Melo. }\end{array}$ & Biblionline \\
\hline O incentivo da leitura na biblioteca escolar & $\begin{array}{l}\text { Diego A. Salcedo; } \\
\text { Jailiny Fernanda Silva Stanford }\end{array}$ & $\begin{array}{l}\text { Revista Brasileira de } \\
\text { Biblioteconomia e } \\
\text { Documentação }\end{array}$ \\
\hline $\begin{array}{l}\text { Guidedinquiry e Construtivismo: novos } \\
\text { métodos de aprendizagem e a biblioteca } \\
\text { escolar }\end{array}$ & $\begin{array}{l}\text { Maria L. Amorim Antunes; } \\
\text { Adriana BoglioloSirihal Duarte. }\end{array}$ & $\begin{array}{l}\text { Biblioteca Escolar } \\
\text { emevista }\end{array}$ \\
\hline $\begin{array}{l}\text { O trabalho cooperativo entre bibliotecários } \\
\text { e professores para o desenvolvimento da da } \\
\text { competência em informação: criação de um } \\
\text { programa voltado para alunos do ensino } \\
\text { médio }\end{array}$ & $\begin{array}{l}\text { Ane Fonseca; } \\
\text { Daniela Spudeit }\end{array}$ & $\begin{array}{l}\text { Biblioteca Escolar } \\
\text { em Revista }\end{array}$ \\
\hline $\begin{array}{l}\text { Políticas públicas e ações de incentivo à } \\
\text { leitura promovidas por organizações } \\
\text { empresariais sob a ótica da } \\
\text { responsabilidade social }\end{array}$ & $\begin{array}{l}\text { Adam Felipe Ferreira; } \\
\text { Claudio Marques Tavares Sardelari; } \\
\text { Filho }\end{array}$ & $\begin{array}{l}\text { Biblioteca Escolar } \\
\text { em Revista }\end{array}$ \\
\hline
\end{tabular}

Fonte: Dados da Pesquisa, 2016.

Foram identificados cinco artigos, dentre o total de 69, somando-se os artigos de todas as últimas edições dos periódicos científicos, o que representa aproximadamente $7,2 \%$ das 
publicações dos periódicos científicos em Biblioteconomia. Doscinco artigos encontrados que abordam o incentivo à leitura,80\% das publicações, ou seja, quatro dos cinco artigos são do periódico Biblioteca Escolar em Revista. Isso mostra a especificidade do periódico em publicar sua temática de origem, ao mesmo tempo em que aponta um baixo número de artigos sobre a temática explorada nos demais periódicos.

Esta análise nos periódicos de biblioteconomia sobre a temática biblioteca escolar/leitura compreende que existem pesquisas indexadas nas mesmas. Porém vale salientar que, em outros canais científicos (eventos acadêmicos e profissionais, bases de dados, publicações internacionais e outros periódicos), podem existir discussões acerca desta temática. Esta pesquisa fez um pequeno panorama das publicações em periódicos específicos. Deixando espaço para possíveis novas análises e novos questionamentos.

\section{CONSIDERAÇÕES FINAIS}

Percebeu-se que a pesquisa científica sobre o incentivo à leitura e bibliotecas escolarestem se mostrado timidamente em periódicos científicos da área. Uma hipótese para tal fato é quea produção científica sobre a temática esteja sendo discutida em outros espaços, como é o caso dos eventos específicos da área.De acordo com a amostra da pesquisa, entretanto, ressalta-se que os periódicos têm qualidade elevada de acordo com os critérios de avaliação Qualis.

Um fator que deve ser considerado é o periódico que tem como fundamento publicações sobre o incentivo à leitura e biblioteca escolar, o que pode ser considerado um fator de impacto da temática dentro da Biblioteconomia. Estudos sobre estes temas necessitam de exploração e cooperação, principalmente dos bibliotecáriosno campo escolar, que propiciam crescimento cultural e informacional. Através da leitura, não só a cultura, mas a formação e a cidadania estão em crescimento e esses são fatores fundamentais para construir a sociedade informacionalde que precisamos.

Como sugestão para pesquisas futuras, a exploração metodológica aplicada em outros tipos de comunicação científica em eventos (encontros, congressos, seminários, simpósios etc.) voltados para o público bibliotecário.

\section{REFERÊNCIAS}

ALMEIDA JÚNIOR, O. F. de. Sociedade e

Biblioteconomia. São Paulo: Polis, 1997.

ARAÙJO, C. S.; SILVA, E. B. F.; SILVA, A. K. A. Práticas de leitura e competências profissionais do bibliotecário: um estudo a partir dos trabalhos de conclusão do Curso de Biblioteconomia / UFPB. Biblionline, n. esp. p. 117-127, 2010. Disponível em: <http://periodicos.ufpb.br/ojs/index.php/bibli o/article/view/9630/5243 >. Acesso em: 10 set. 2016.

DUARTE, E. N. Análise da produção científica em gestão do conhecimento: estratégias metodológicas e estratégias organizacionais. 2003. Tese (Doutorado em Administração). Universidade Federal da Paraíba. João Pessoa, 2003.

\section{GIL, A. C. Como elaborar projetos de} pesquisa. 4. ed. São Paulo: Atlas, 2002.

LEITE, L. R. T. Biblioteca escolar como extensão do processo de ensinoaprendizagem: percepções da comunidade docente do colégio de aplicação da UFSC. Revista ACB: Biblioteconomia em Santa Catarina, v. 21, n. 1, 2016. Disponível em: <https://revista.acbsc.org.br/racb/article/view/ 1162>. Acesso em: 17 set. 2016.

MARCONI, M de A.; LAKATOS, E. M. Fundamentos de metodologia científica. 4. Ed. São Paulo: Atlas, 2003.

MUELLER, S. P. M.; CAMPELLO, B. S.; DIAS, E. J. W. Disseminação da pesquisa em Ciência da Informação e Biblioteconomia no 
Brasil. Ciência da Informação, v. 25, n. 3, p. 23, 1996.

OLIVEIRA, I. R.; CAMPELLO, B. S. Estado da arte sobre pesquisa escolar no Brasil.

Transinformação, v. 28, n. 2, 2016.

Disponível em: <http://periodicos.puccampinas.edu.br/seer/index.php/transinfo/arti cle/view/2416/2260>. Acesso em: 17 set. 2016.

SANTOS, C. B. Bibliotecas escolares: políticas públicas para a criação de possibilidades. Tendências da Pesquisa Brasileira em Ciência da Informação, v. 8, n. 2, 2015. Disponível em:

$<$ https://periodicos.ufsc.br/index.php/eb/articl e/view/1518-2924.2013v18n37p123/25335>. Acesso em: 17 set. 2016.

SILVA, J. D. O.; CUNHA, J. A. O papel educativo da biblioteca escolar no contexto do plano nacional de educação. Encontros Bibli: Revista Eletrônica de Biblioteconomia e Ciência da Informação, v. 21, n. 46, p. 45-58, 2016. Disponível em:

$<$ https://periodicos.ufsc.br/index.php/eb/articl e/view/38695>. Acesso em: 17 set. 2016.

SILVA, L. V. PIERUCCINE, I.

BIBLIOTECAS ESCOLARES: políticas públicas para criação de possibilidades.

Tendências da Pesquisa Brasileira em Ciência da Informação, v. 8, n. 2. 2015. Disponível em:

$<$ http://inseer.ibict.br/ancib/index.php/tpbci/ar ticle/viewArticle/202>. Acesso em: 10 set. 2016.

SILVA, R. J. Formar leitores na escola: o projeto pedagógico, a biblioteca escolar e a mediação. Informação \& Informação, v. 20, n. 3, 2015. Disponível em:

<http://www.uel.br/revistas/uel/index.php/inf ormacao/article/view/15390 > . Acesso em: 17 set. 2016.

SILVA, R. J.; TENÓRIO, G. O. Biblioteca escolar e mediação de leitura: uma proposta de fichas pedagógicas de registro dos livros. Informação@ Profissões, v. 3, n. 1-2, 2014. Disponível em:
$<$ http://www.uel.br/revistas/uel/index.php/inf ormacao/article/view/1539>. Acesso em: 17 Set. 2016. 